\title{
TEMPORAL AND SPATIAL CHANGES OF HIGH TEMPERATURE HAZARD AFFECTING SINGLE-SEASON RICE IN JIANGXI PROVINCE, SOUTHEAST CHINA
}

\author{
YANG, J. ${ }^{1}-$ ZHANG, Y.Z. ${ }^{1}-$ LI, Y.C. ${ }^{1}-$ LIU, D. ${ }^{1}-$ JIN, G. H. ${ }^{1}-$ TIAN, J. ${ }^{1}-$ LI, X. X. ${ }^{2}-$ HUANG, S. E. ${ }^{1 *}$ \\ ${ }^{1}$ Meteorological Science Research Institute of Jiangxi Province, Nanchang 330096, China \\ ${ }^{2}$ Agro-Meteorological Center of Jiangxi Province, Nanchang 330096, China \\ *Corresponding author \\ e-mail:512675442@qq.com
}

(Received 12 $2^{\text {th }}$ Apr 2020; accepted $10^{\text {th }}$ Jul 2020)

\begin{abstract}
High temperature (HT), considered a daily average temperature $\left(\mathrm{T}_{\text {ave }}\right) \geq 30{ }^{\circ} \mathrm{C}$ or a daily maximum temperature $\left(\mathrm{T}_{\max }\right) \geq 35{ }^{\circ} \mathrm{C}$, during the heading-flowering period affects single-season rice production in Jiangxi Province, southeast China, and the temporal and spatial changes of HT are not yet clear in this province. Here, the meteorological data of 85 national weather stations from 1981 to 2017 were used to explore the temporal and spatial changes of HT. In addition, the effects of HT during the heading-flowering period on yield and spikelet fertility of single-season rice were investigated. Our results showed that HT in single-season rice occurred every year from 1981 to $2017 . \mathrm{T}_{\text {ave }}, \mathrm{T}_{\max }$, and HT hazard events (HT for $\geq$ three consecutive days) increased after 2003, with severe HT (HT for $\geq$ eight consecutive days) increasing significantly. In addition, a greater number of HT hazard events were mainly distributed in the middle and northeast area of Jiangxi. HT mainly occurred from July 11 to August 10, and severe HT occurred more frequently from July 21 to July 31. It is worth noting that there were strong negative correlations between spikelet fertility and $\mathrm{T}_{\text {ave }}$, days of $\mathrm{T}_{\text {ave }} \geq 30{ }^{\circ} \mathrm{C}$, and days of $\mathrm{T}_{\max } \geq 35^{\circ} \mathrm{C}$. Thus, these results should be considered for establishing effective strategies to mitigate rice HT hazard under global climate change.
\end{abstract}

Keywords: rice, high temperature, flowering, spikelet fertility, sowing date

\section{Introduction}

Rice (Oryza sativa L.) is the staple food source for more than half of the world's population. Recently, extreme high temperature (HT) events frequently affect rice production (Kim et al., 2013; Espe et al., 2017). HT beyond the critical threshold $\left(\mathrm{T}_{\text {ave }} \geq 30{ }^{\circ} \mathrm{C}\right.$ or $\mathrm{T}_{\max } \geq 35{ }^{\circ} \mathrm{C}$ ) during the growth period, especially during the headingflowering period, leads to poor fertilization and reduced spikelet fertility, which drastically reduces rice yield (Jagadish et al., 2010; Madan et al., 2012; Chaturvedi et al., 2017; Zhao et al., 2018; Stuerz and Asch, 2019). Rice grain yield could decline by $10 \%$ for each $1{ }^{\circ} \mathrm{C}$ increase in the nighttime temperature (Peng et al., 2004). Globally, the average surface temperature has increased by $0.85{ }^{\circ} \mathrm{C}$ from 1880 to 2012 (IPCC, 2013). The frequency or intensity of HT events will likely continue to increase, which could lead to the higher vulnerability of rice (Van Oort et al., 2018). Thus, current research should be focused on reducing the loss of rice yield under HT events (Ray et al., 2015; Wang et al., 2016).

Jiangxi is one of the most important two-season rice producing provinces in southeast China, as it can deliver rice to the country year-round. In recent years, due to urbanization and the shortage of the rural labor force, the production area of two-season rice has been decreasing, whereas the production area of single-season rice in Jiangxi has exceeded 460,000 hectares and is expected to increase in the future. However, HTs 
caused by the Pacific sub-tropical high during the heading-flowering period from July to August every year in Jiangxi tend to occur frequently, which can easily lead to HT hazard causing a huge loss of single-season rice yield (Huang et al., 2017). Therefore, improving HT resistance of single-season rice has received increasing attention.

HT is not conducive to rice production, but taking effective defense measures can reduce HT hazard (Khan et al., 2019). Previous studies have shown that the selection of heat-resistant varieties (Prasad et al., 2006; Jagadish et al., 2010), improvement of field management (Yang et al., 2015; Tang et al., 2019), and application of exogenous substances (Mohammed et al., 2009; Fahad et al., 2016; Wu et al., 2017) can effectively mitigate the negative effects of HT on rice growth and development. In addition, avoiding HT during the heading-flowering period, by varying flowering times, is another effective method against HT hazard. Rice with an early-morning flowering (EMF) trait could avoid HT-induced sterility during anthesis by flowering at a cooler temperature in the early morning (Ishimaru et al., 2010). It has been reported that EMF rice with a quantitative trait locus (QTL) named $q E M F 3$ mitigated heat-induced spikelet sterility under elevated temperature by completing flower opening before the air temperature reached $35^{\circ} \mathrm{C}$ during the day (Hirabayashi et al., 2015).

Previous studies have been conducted on rice HT hazard in Jiangxi. By investigating the temperature data of 74 meteorological stations in Jiangxi from June to August from 1961 to 2010, Yang et al. (2012) showed that the annual frequency of occurrence of rice heat stress decreased from 1961 to 1982, while increased significantly from 1983 to 2010. Moreover, Huang et al. (2017) indicated that the changes of intensity of HT hazard events were significant, the higher hazard events for rice heat stress were mainly detected in the middle and northeast area of Jiangxi. However, the temporal and spatial changes of HT hazard affecting single-season rice in Jiangxi were still not well analyzed.

In the present study, we used meteorological data of 85 national weather stations from July to August 1981 to 2017 to (1) comprehensively investigate temporal and spatial changes of HT hazard affecting single-season rice during the heading-flowering period in Jiangxi Province, (2) study the effects of HT on yield and spikelet fertility of single-season rice, and (3) find the highest risk period to avoid HT hazard. Thus, the overall objective of this study is to provide the scientific support for the high- and stable-yield cultivation and HT resistance of single-season rice under global warming.

\section{Material and methods}

\section{Data collection}

Jiangxi Province (latitude: $24^{\circ} 29^{\prime} \mathrm{N}-30^{\circ} 05^{\prime} \mathrm{N}$, longitude: $113^{\circ} 34^{\prime} \mathrm{E}-118^{\circ} 29^{\prime} \mathrm{E}$ ) located in southeast China is dominated by a humid subtropical monsoon climate; thus, the climate is mild with abundant sunshine and rainfall. Moreover, the four seasons are evident and there is a long frost-free period (240-307 days), making Jiangxi conducive to the cultivation of crops. The average annual temperature, average annual precipitation, and average annual illumination time are $16.5-19.8^{\circ} \mathrm{C}, 1,436-1,956 \mathrm{~mm}$, and 1,327-1,927 h, respectively (Huang et al., 2017). In Jiangxi, rice can be grown as either double cropping (early or late rice) or single cropping (single-season rice). The HTs in summer (from June to August) are likely to trigger heat stress response of early rice during the grain filling period and single-season rice during the heading-flowering period. 
The meteorological data of daily average temperature $\left(\mathrm{T}_{\text {ave }}\right)$ and daily maximum temperature $\left(\mathrm{T}_{\max }\right.$ ) of 85 national weather stations (Fig. 1) from July 11, 1981 to August 31, 2017, in Jiangxi Province were provided by the Jiangxi Meteorological Bureau. The agricultural data of single-season rice yield in seven representative regional trial sites (Fuliang, Anyi, Nanchang, Fuzhou, Pingxiang, Ji'an, and Huichang) (Fig. 1) over 13 years (2004-2016) were collected from the Department of Agriculture of Jiangxi Province.

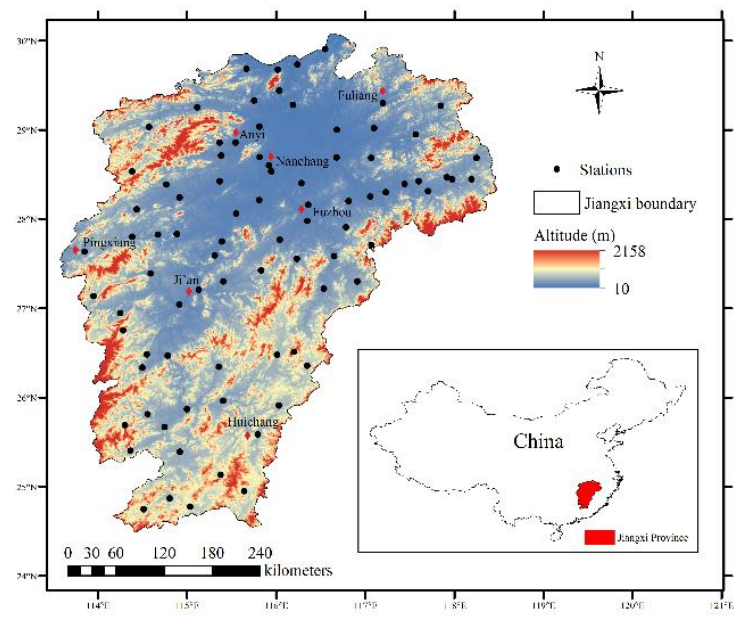

Figure 1. Distribution of 85 national weather stations in Jiangxi Province, southeast China

\section{Analytical methods}

\section{Temperature anomalies}

The daily $\mathrm{T}_{\text {ave }}$ and $\mathrm{T}_{\max }$ data from July 11, 1981 to August 31, 2017, were compiled to analyze the temporal and spatial changes of temperature, temperature anomaly (the difference between an observed temperature and the average temperature), and accumulative anomaly (sum of the anomalies). Within the calculated temperature anomalies, the low, medium, and high anomalies were separated, where a low temperature anomaly was considered $\leq-0.50^{\circ} \mathrm{C}$, a medium temperature anomaly was $0.5-0.5^{\circ} \mathrm{C}$, and a high anomaly was $\geq 0.50{ }^{\circ} \mathrm{C}$.

\section{HT hazard}

$\mathrm{T}_{\text {ave }} \geq 30{ }^{\circ} \mathrm{C}$ or $\mathrm{T}_{\max } \geq 35{ }^{\circ} \mathrm{C}$ were considered the threshold for HT (Jagadish et al., 2010; Madan et al., 2012), and HT for three to four consecutive days was defined as slight HT hazard, five to seven consecutive days for moderate HT hazard, and $\geq$ eight consecutive days for severe HT hazard. Furthermore, the temporal and spatial changes of the number of stations recording the occurrence of HT hazard; the number of slight, moderate, and severe HT hazard; the number of HT days; and the greatest number of consecutive HT days at 85 national weather stations from 1981 to 2017 were analyzed.

\section{Measures of single-season rice yield}

Based on the changes in temperature, the changes in the annual yield of singleseason rice (effective panicles, total grains per panicle, filled grains per panicle, spikelet 
fertility, 1000-grain weight, and yield) (Prasad et al., 2006) were analyzed to screen for effective traits for the identification of HT hazard during the heading-flowering period.

\section{Statistical analysis}

Excel2010, Matlab 2010a, and ArcGIS10.2 software (Huang et al., 2017) were used to analyze data and draw graphs. The correlations between meteorological parameters and rice yield were conducted by using SPSS 17.0 (Yang et al., 2015). The significance was determined using the least significant difference (LSD) test at $\mathrm{P}<0.05$ or $\mathrm{P}<0.01$, which was calculated using SPSS 17.0.

\section{Results}

\section{Temporal changes of temperature anomalies}

The temporal changes of $\mathrm{T}_{\text {ave }}$ and $\mathrm{T}_{\max }$ anomalies show a consistent trend (Fig. $2 a$ and $b$ ). The temperature anomalies and accumulative anomalies could be divided into three periods: normal temperature (1981-1992), low temperature (1993-2002), and HT (2003-2017). During the normal temperature period, the temperature anomalies and accumulative anomalies were relatively stable with 11 medium anomalies $\left(-0.5-0.5^{\circ} \mathrm{C}\right)$ of $\mathrm{T}_{\text {ave }}$ and six medium anomalies of $\mathrm{T}_{\max }$. During this period, the average anomaly of $\mathrm{T}_{\text {ave }}$ and $\mathrm{T}_{\max }$ were $0.04{ }^{\circ} \mathrm{C}$ and $0.18{ }^{\circ} \mathrm{C}$, respectively. During the low temperature period, the accumulative anomalies showed a downward trend with six low anomalies $\left(\leq-0.50{ }^{\circ} \mathrm{C}\right)$ of $\mathrm{T}_{\text {ave }}$ and seven low anomalies of $\mathrm{T}_{\max }$; the average anomaly of $\mathrm{T}_{\text {ave }}$ and $\mathrm{T}_{\max }$ during this period was $-0.60{ }^{\circ} \mathrm{C}$ and $-0.91{ }^{\circ} \mathrm{C}$, respectively. During $\mathrm{HT}$ period, the accumulative anomalies showed an upward trend with six high anomalies $\left(\geq 0.50^{\circ} \mathrm{C}\right)$ of $\mathrm{T}_{\text {ave }}$ and seven high anomalies of $\mathrm{T}_{\max }$, and the average anomaly of $\mathrm{T}_{\text {ave }}$ and $\mathrm{T}_{\max }$ were $0.37^{\circ} \mathrm{C}$ and $0.47^{\circ} \mathrm{C}$, respectively. The increasing occurrence of temperature anomalies during the current HT period indicated that the $\mathrm{T}_{\text {ave }}$ and $\mathrm{T}_{\max }$ have generally risen since $2003(\mathrm{P}<0.05)$.
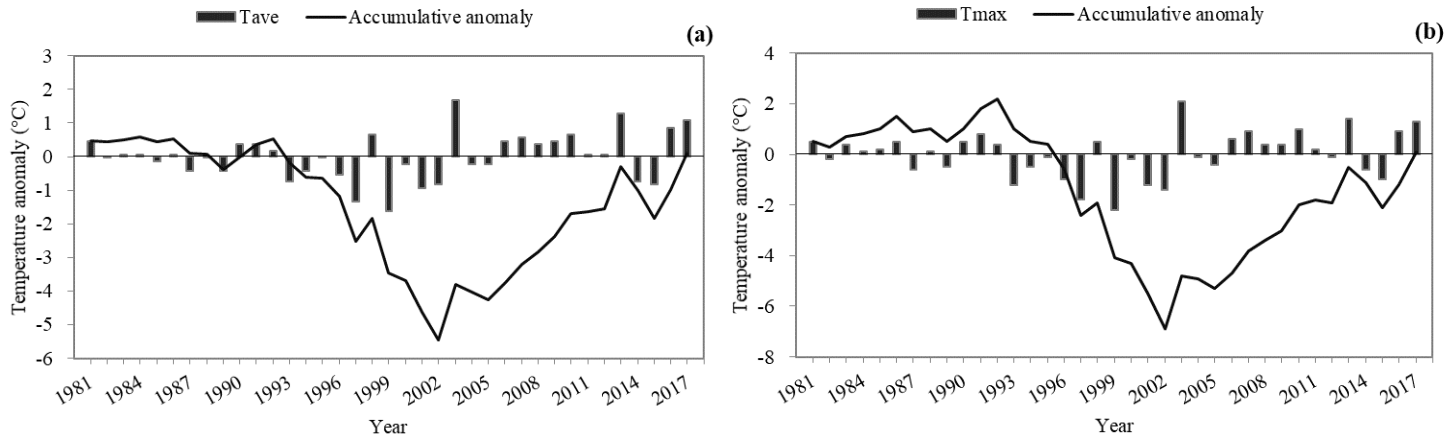

Figure 2. Temporal changes of $T_{\text {ave }}(a)$, and $T_{\max }(b)$ anomalies from 1981 to $2017^{\dagger} \cdot{ }^{\dagger} T_{\text {ave: }}$ : daily average temperature; $T_{\text {max }}$ : daily maximum temperature. Accumulative anomaly is the accumulation of anomalies

\section{Spatial distribution of temperature anomalies}

The spatial distribution of $\mathrm{T}_{\text {ave }}$ anomalies is consistent with that of the $\mathrm{T}_{\max }$ anomalies (Fig. $3 a$ and $b$ ). The temperature anomalies were spatially divided into low anomaly zone, medium anomaly zone, and high anomaly zone. The medium anomaly zone $\left(-0.5-0.5{ }^{\circ} \mathrm{C}\right)$ 
covered most of the province with 45 stations of $\mathrm{T}_{\text {ave }}$ and 49 stations of $\mathrm{T}_{\max }$. The average anomaly of $\mathrm{T}_{\text {ave }}$ and $\mathrm{T}_{\max }$ in this zone were $0.47{ }^{\circ} \mathrm{C}$ and $0.11{ }^{\circ} \mathrm{C}$, respectively. Fifteen stations of $\mathrm{T}_{\text {ave }}$ and 19 stations of $\mathrm{T}_{\max }$ belonged to the low anomaly zone $\left(\leq-0.50{ }^{\circ} \mathrm{C}\right)$, and the average anomaly of $\mathrm{T}_{\text {ave }}$ and $\mathrm{T}_{\max }$ in this zone were $-1.21{ }^{\circ} \mathrm{C}$ and $-0.87{ }^{\circ} \mathrm{C}$, respectively. The high anomaly zone $\left(\geq 0.50{ }^{\circ} \mathrm{C}\right)$ was primarily located in the middle and northeast of the province with 25 stations of $\mathrm{T}_{\text {ave }}$ and 17 stations of $\mathrm{T}_{\max }$, and the average anomaly of $\mathrm{T}_{\text {ave }}$ and $\mathrm{T}_{\max }$ in this zone were $0.74^{\circ} \mathrm{C}$ and $0.70{ }^{\circ} \mathrm{C}$, respectively.
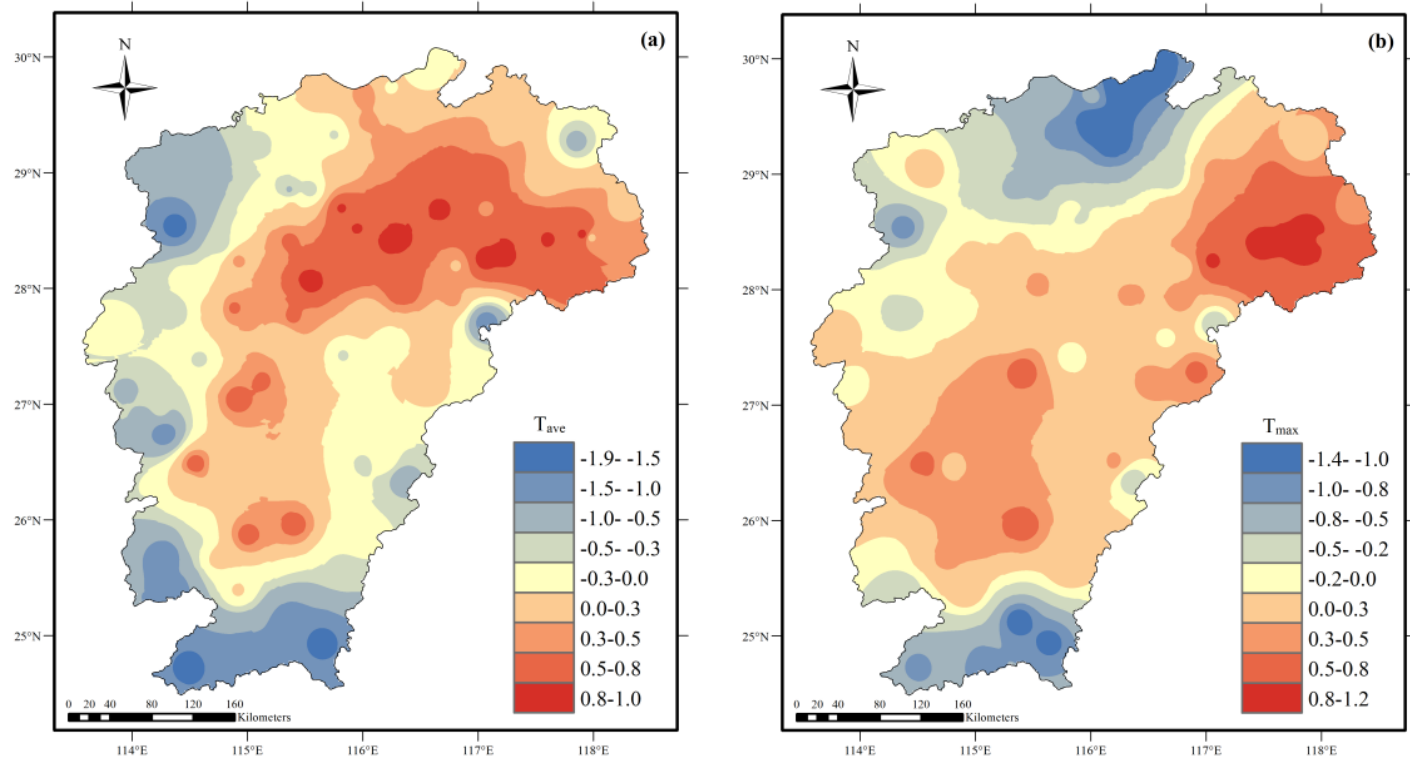

Figure 3. Spatial distribution of $T_{\text {ave }}(a)$, and $T_{\max }(b)$ anomalies from 1981 to $2017^{\dagger} .{ }^{\dagger} T_{\text {ave: }}$ daily average temperature; $T_{\max }$ : daily maximum temperature

\section{Changes of daily temperature}

The changes of daily $\mathrm{T}_{a v e}$ and $\mathrm{T}_{\max }$ are similar, showing a trend of increasing first and then decreasing (Fig. 4). The $\mathrm{T}_{\text {ave }}$ and $\mathrm{T}_{\max }$ were $29.3{ }^{\circ} \mathrm{C}$ and $34.5{ }^{\circ} \mathrm{C}$ from July 11 to August 10, and $28.0{ }^{\circ} \mathrm{C}$ and $33.0{ }^{\circ} \mathrm{C}$ from August 11 to August 31 from 1981-2017, indicating that $\mathrm{T}_{a v e}$ and $\mathrm{T}_{\max }$ in mid-July to early-August were higher than that in midto late-August. The data presented in Figure 4 also indicate that the temperatures of four consecutive days on July 22-25 were the highest $\left(\mathrm{T}_{\text {ave }} \geq 29.6{ }^{\circ} \mathrm{C}, \mathrm{T}_{\max } \geq 34.9{ }^{\circ} \mathrm{C}\right.$ ), especially the $\mathrm{T}_{\max }$ of three consecutive days from July $23-25$, which exceeded $35^{\circ} \mathrm{C}$. Thus, it is necessary to attend to the effects of HT on heading and flowering in singleseason rice from July 22 to July 25 each year.

\section{Temporal changes of the number of stations recording the occurrence of HT hazard}

Many stations showed record of slight and moderate HT hazards each year, but no severe HT hazard events occurred in 1997 and 1999. In 1997, the number of stations recording the occurrence of HT hazard events was the lowest, with only 31 stations recording HT hazard events. In contrast, the slight, moderate, and severe HT hazard events occurred at all 85 stations in 2003 (Fig. 5). During the normal temperature period (1981-1992), the average number of stations recording the occurrence of slight, moderate, and severe HT hazard events was 80.92 stations, 73.75 stations, and 56.50 
stations, respectively. The average number of stations recording HT hazard events was 73.80 stations showing slight HT, 60.10 stations with moderate HT, 31.50 stations showing severe HT during the low temperature period (1993-2002), and 84.67 stations showing slight, 81.13 stations recording moderate, 62.80 stations recording severe during the HT period (2003-2017). The above results indicate that the number of stations recording the occurrence of slight, moderate, and severe HT hazard events have increased since $2003(\mathrm{P}<0.05)$.

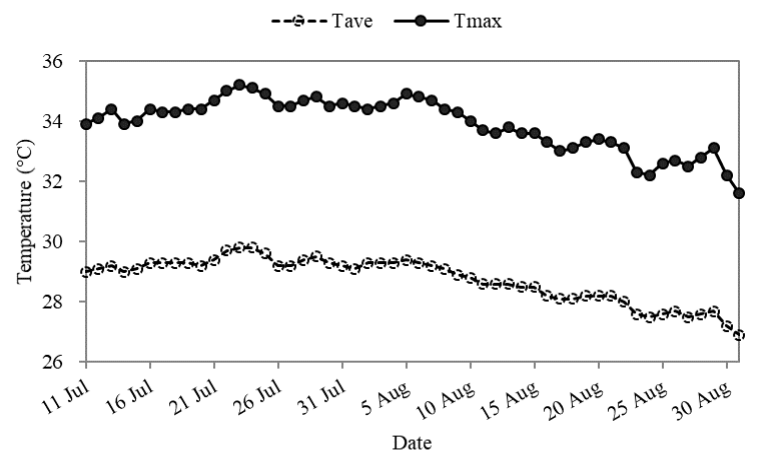

Figure 4. Changes of daily temperature ${ }^{\dagger}{ }^{\dagger} T_{\text {ave }}$ : daily average temperature; $T_{\max }$ : daily maximum temperature

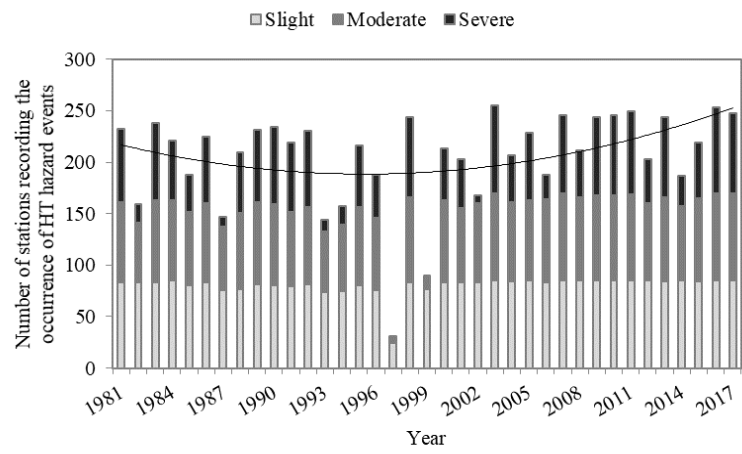

Figure 5. Temporal changes of the number of stations recording the occurrence of slight, moderate, and severe HT hazard events from 1981 to $2017^{\prime} .{ }^{\dagger} H T$ : high temperature. $T_{\text {ave: }}$ daily average temperature; $T_{\max }$ : daily maximum temperature. $T_{\text {ave }} \geq 30^{\circ} \mathrm{C}$ or $T_{\max } \geq 35^{\circ} \mathrm{C}$ for three to four days is considered a slight HT hazard, five to seven consecutive days for moderate HT hazard, $\geq$ eight consecutive days for severe HT hazard

\section{Temporal changes of the number of HT hazard events}

Over the past 37 years (1981-2017), HT hazard occurred every year in this province. The number of slight HT hazards was the highest (95.59), followed by moderate HT hazards (79.19), and severe HT hazards (72.45). In 1997, the total number of HT hazard events was the lowest, with only 33 recorded HT hazard events. In contrast, the number of HT hazard events in 2006 was the highest, reaching 405 (Fig. 6). During the normal temperature period (1981-1992), the average number of HT hazard events of slight, moderate, and severe HT hazards was 84.08, 82.17, and 68.23, respectively. The average number of HT hazard events for slight, moderate, and severe HT hazard events was 89.40, 65.70, and 41.90 during the low temperature period (1993-2002), and 
108.93, 85.80, and 93.73 during the HT period (2003-2017), respectively. This indicates that the number of slight, moderate, and severe HT hazard events has increased since 2003, with severe HT hazard events increasing significantly $(\mathrm{P}<0.05)$.



Figure 6. Temporal changes of the number of HT hazard events from 1981 to $2017^{\dagger} .{ }^{\dagger} H T$ : high temperature. $T_{\text {ave: }}$ daily average temperature; $T_{\text {max }}$ : daily maximum temperature. $T_{\text {ave }} \geq 30^{\circ} \mathrm{C}$ or $T_{\max } \geq 35^{\circ} \mathrm{C}$ for three to four days is considered a slight HT hazard, five to seven consecutive days for moderate HT hazard, $\geq$ eight consecutive days for severe HT hazard

\section{Temporal distribution of the number of HT hazard events}

Figure 7 shows that slight, moderate, and severe HT hazard events occurred in every time period (i.e., every ten days) from July 11 to August 31 in the past 37 years. The overall number of slight HT hazard events was the highest (128.97), followed by moderate HT hazards (96.35), and severe HT hazards (62.14). HT hazard events primarily occurred from July 11 to August 10, and the number of HT hazard events during the time period was 211.70 , accounting for $73.65 \%$ of the total number of events. Therefore, during the heading-flowering period of rice, which falls from July 11 to August 10, the hot weather should be attended to avoid HT hazard. The fewest slight, moderate, and severe HT hazard events (33.95) occurred from August 11 to August 20, and the greatest number of HT hazard events (74.32) appeared from July 21 to July 31. The number of severe HT hazard events from July 21 to July 31 was 28.16, accounting for $45.32 \%$ of the total severe HT hazard events, indicating that this area is prone to severe HT hazard events from July 21 to July 31.



Figure 7. Distribution of the number of HT hazard events of temporal periods (every ten days) ${ }^{*}$. ${ }^{\prime} H T$ : high temperature. $T_{\text {ave: }}$ daily average temperature; $T_{\text {max }}$ : daily maximum temperature. $T_{\text {ave }} \geq 30{ }^{\circ} \mathrm{C}$ or $T_{\max } \geq 35^{\circ} \mathrm{C}$ for three to four days is considered a slight HT hazard, five to seven consecutive days for moderate HT hazard, $\geq$ eight consecutive days for severe HT hazard 


\section{Spatial distribution of the number of HT hazard events}

The east, south, and west of Jiangxi Province are surrounded by mountains, and the north is flat, forming a large open basin that is tilted to the north. The spatial distribution of the number of HT hazard events is closely related to the topography, with more HT hazard events in plains and basins and fewer in mountains (Fig. 8). The spatial distribution of the total number of HT hazard events and the number of slight, moderate, and severe HT hazards (Fig. $8 a-d$ ) are similar, meaning that the area with a high frequency of HT hazard events is mainly distributed in the middle and northeast of this province. The total number of HT hazard events in the high frequency area was 155-174. The number of slight, moderate, and severe HT hazard events in the middle and northeast of the province were 78-86, 52-59, and 27-33, respectively. Thus, special attention should be paid to areas with a greater tendency to have HT hazard events during the heading-flowering period from July 11 to August 10 in single-season rice.
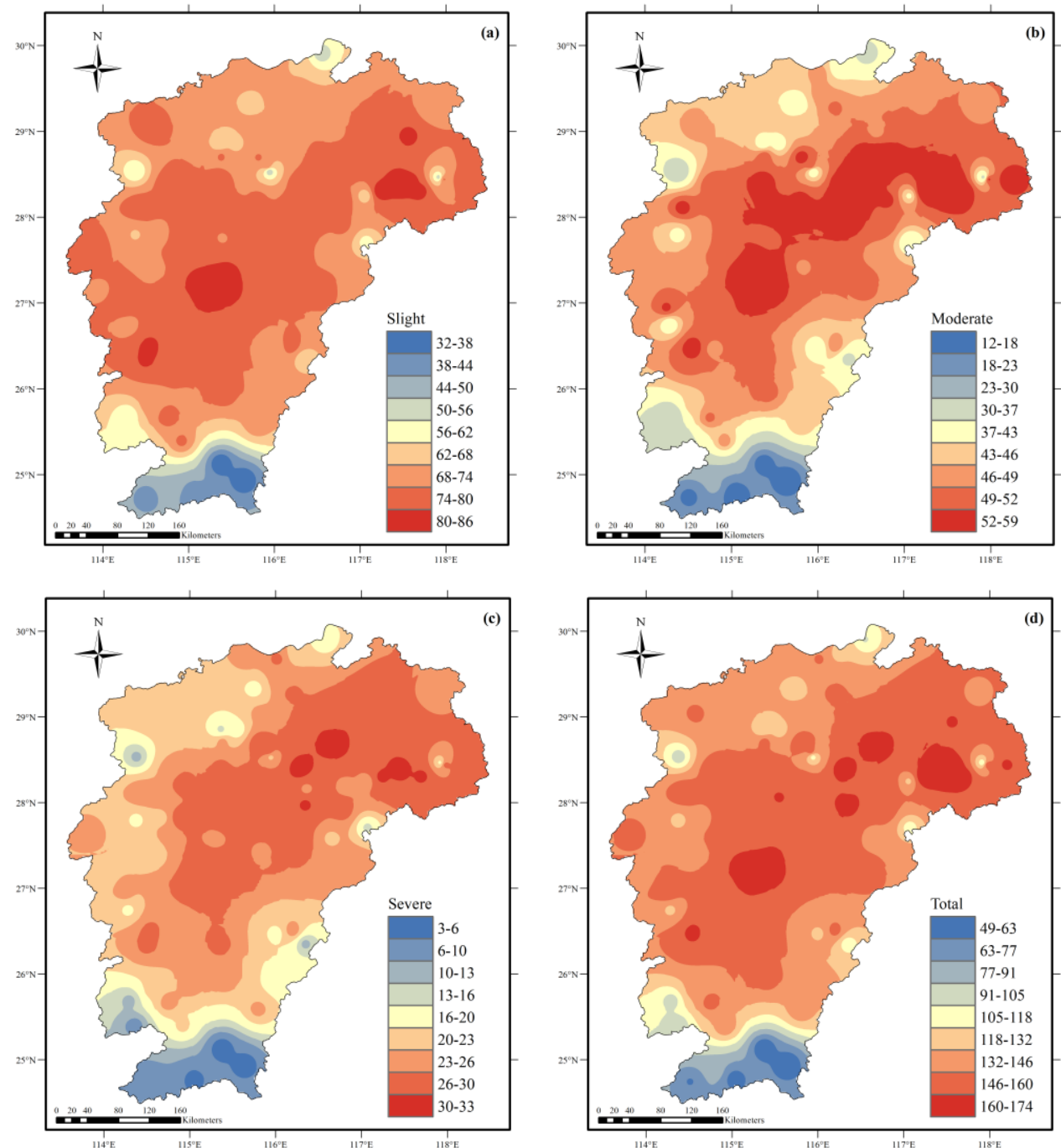

Figure 8. Spatial distribution of the number of slight (a), moderate (b), severe (c), and total (d) HT hazard events from 1981 to $2017^{\prime} .{ }^{\dagger} \mathrm{HT}$ : high temperature. $T_{\text {ave: }}$ : daily average temperature;

$T_{\max }$ : daily maximum temperature. $T_{\text {ave }} \geq 30{ }^{\circ} \mathrm{C}$ or $T_{\max } \geq 35^{\circ} \mathrm{C}$ for three to four days is considered a slight HT hazard, five to seven consecutive days for moderate HT hazard, $\geq$ eight consecutive days for severe HT hazard 


\section{Temporal changes of the number of $H T$ days and the greatest number of consecutive HT days}

The temporal changes of the number of HT days of $\mathrm{T}_{a v e} \geq 30{ }^{\circ} \mathrm{C}$ is consistent with that of $\mathrm{T}_{\max } \geq 35{ }^{\circ} \mathrm{C}$ (Fig. $9 a$ and $b$ ). During the normal temperature period (1981-1992), the average number of HT days of $\mathrm{T}_{\text {ave }}$ and $\mathrm{T}_{\max }$ were $16.14 \mathrm{~d}$ and $21.36 \mathrm{~d}$, respectively. The average number of HT days was $11.74 \mathrm{~d}\left(\mathrm{~T}_{\text {ave }}\right)$ and $15.08 \mathrm{~d}$ $\left(\mathrm{T}_{\max }\right)$ during the low temperature period (1993-2002), and $20.08 \mathrm{~d}\left(\mathrm{~T}_{\text {ave }}\right)$ and $25.67 \mathrm{~d}$ ( $\mathrm{T}_{\max }$ ) during the HT period (2003-2017). The number of HT days of $\mathrm{T}_{\text {ave }}$ and $\mathrm{T}_{\max }$ in 1997 was the lowest, with only $1.35 \mathrm{~d}$ and $3.78 \mathrm{~d}$, and the number of HT days in 2003 was the highest, reaching $32.31 \mathrm{~d}$ and $36.44 \mathrm{~d}$, respectively. After 2003, the number of HT days showed an overall increase $(\mathrm{P}<0.05)$.

The temporal changes of the greatest number of consecutive days of $\mathrm{T}_{\text {ave }} \geq 30{ }^{\circ} \mathrm{C}$ and $\mathrm{T}_{\max } \geq 35{ }^{\circ} \mathrm{C}$ is similar (Fig. $9 a$ and $b$ ). During the normal temperature period (1981-1992), the greatest number of consecutive days of $\mathrm{T}_{\text {ave }}$ and $\mathrm{T}_{\max }$ were $7.88 \mathrm{~d}$ and $9.70 \mathrm{~d}$ on average, respectively. The average number of days was $5.18 \mathrm{~d}\left(\mathrm{~T}_{\text {ave }}\right)$ and $6.38 \mathrm{~d}\left(\mathrm{~T}_{\max }\right)$ during the low temperature period (1993-2002), and $9.19 \mathrm{~d}\left(\mathrm{~T}_{\text {ave }}\right)$ and $10.98 \mathrm{~d}\left(\mathrm{~T}_{\max }\right)$ during the HT period (2003-2017). The data presented in Figure 9 also shows that the greatest number of consecutive days of $\mathrm{T}_{\text {ave }}$ and $\mathrm{T}_{\max }$ in 1997 was the lowest, with only $0.71 \mathrm{~d}$ and $1.80 \mathrm{~d}$, and the greatest number of consecutive days in 2003 was the highest, reaching $18.22 \mathrm{~d}$ and $20.94 \mathrm{~d}$, respectively. Overall, the number of HT days showed an increase since $2003(\mathrm{P}<0.05)$.
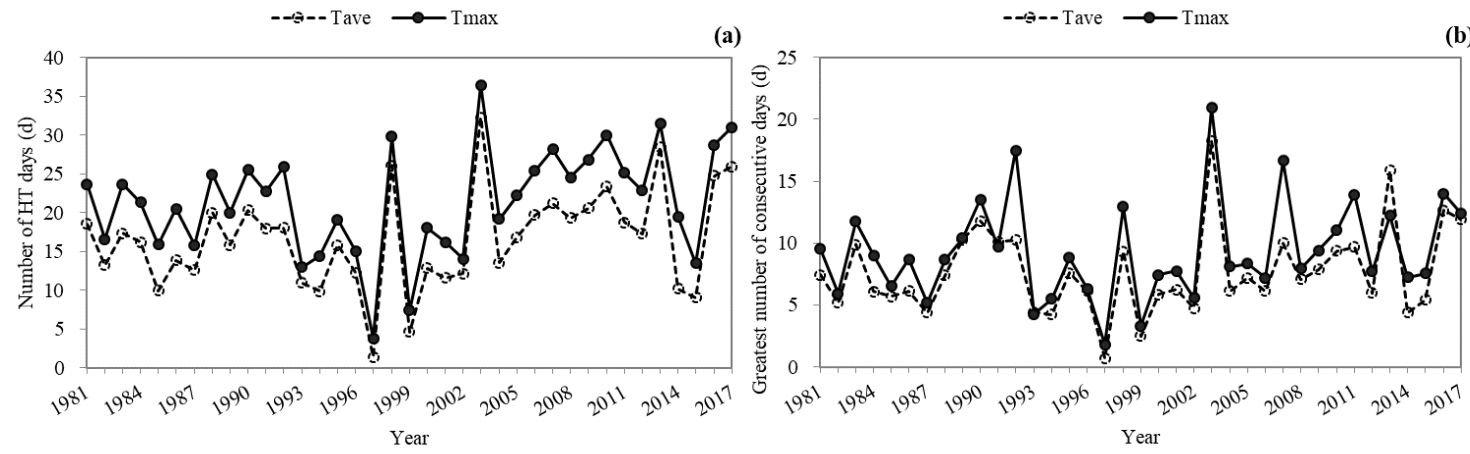

Figure 9. Temporal changes of the number of HT days (a), and the greatest number of consecutive HT days (b) from 1981 to $2017^{\dagger} .{ }^{\dagger} H T$ : high temperature. $T_{\text {ave: }}$ daily average temperature; $T_{\max }$ : daily maximum temperature. The number of $H T$ days is the number of days of $T_{\text {ave }} \geq 30^{\circ} \mathrm{C}$ or $T_{\max } \geq 35^{\circ} \mathrm{C}$. The greatest number of consecutive HT days is the number of consecutive days of $T_{\text {ave }} \geq 30^{\circ} \mathrm{C}$ or $T_{\max } \geq 35^{\circ} \mathrm{C}$

\section{Spatial distribution of the number of HT days and the greatest number of consecutive HT days}

Figure 10 shows that the spatial distribution of the number of HT days of $\mathrm{T}_{\text {ave }} \geq 30{ }^{\circ} \mathrm{C}$ and $\mathrm{T}_{\max } \geq 35{ }^{\circ} \mathrm{C}$ is consistent with that of the greatest number of consecutive HT days. The number of HT days and the greatest number of consecutive days of $\mathrm{T}_{\text {ave }} \geq 30^{\circ} \mathrm{C}$ were $16.67 \mathrm{~d}$ and $7.72 \mathrm{~d}$, respectively (Fig. 10a and $b$ ). The number of HT days and the greatest number of consecutive days of $\mathrm{T}_{\max } \geq 35{ }^{\circ} \mathrm{C}$ were $21.49 \mathrm{~d}$ and $9.35 \mathrm{~d}$, respectively (Fig. 10c and $d$ ). The number of HT days ( $\geq 21$ days of $\mathrm{T}_{\text {ave }} \geq 30{ }^{\circ} \mathrm{C}$ or $\geq 24$ days of $\mathrm{T}_{\max } \geq 35^{\circ} \mathrm{C}$ ) and the greatest number of consecutive days 
( $\geq$ nine days of $\mathrm{T}_{\text {ave }} \geq 30{ }^{\circ} \mathrm{C}$ or $\geq 10.5$ days of $\mathrm{T}_{\max } \geq 35^{\circ} \mathrm{C}$ ) were mainly distributed in the middle and northeast area of this province.
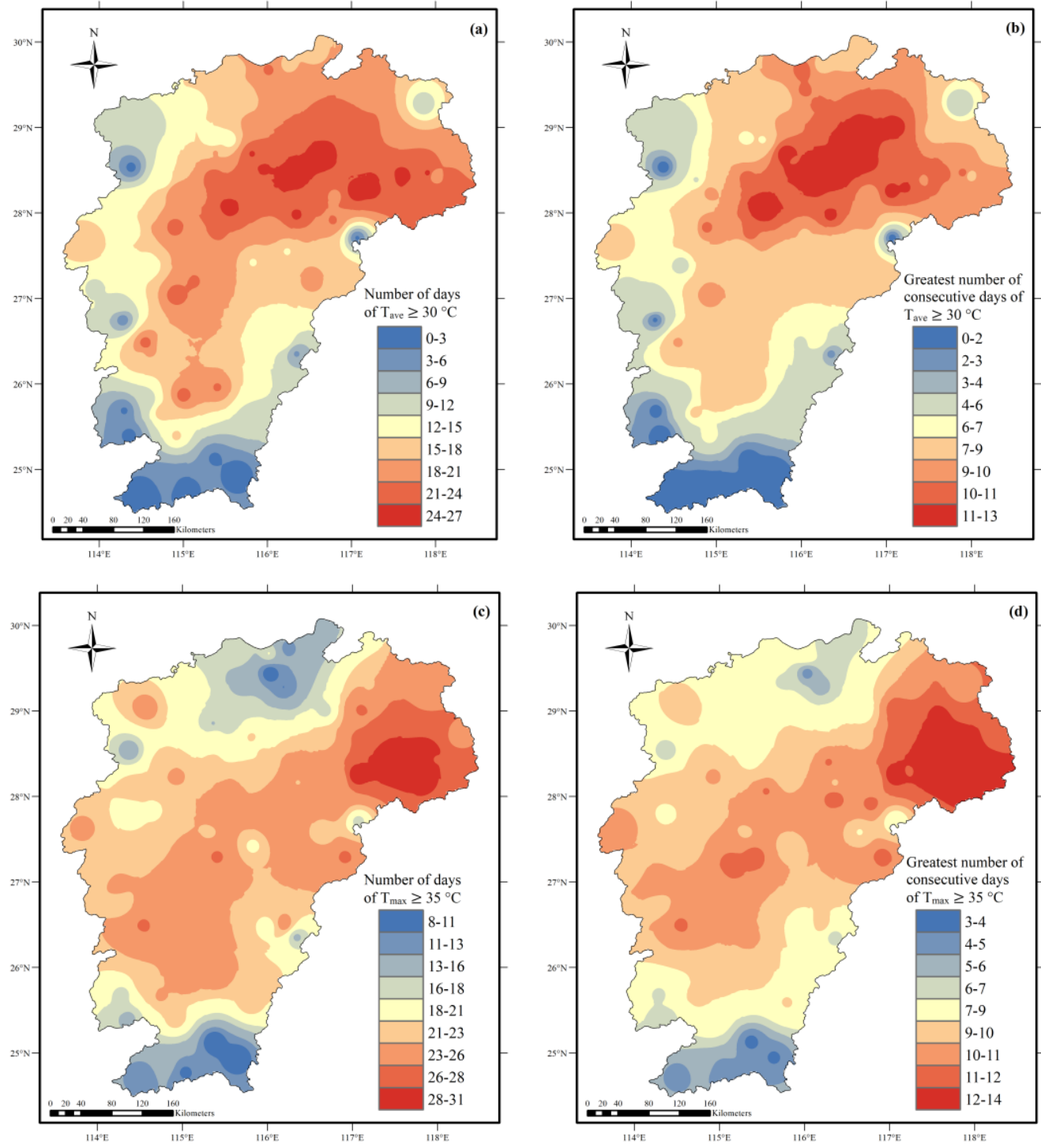

Figure 10. Spatial distribution of the number of days of $T_{\text {ave }} \geq 30^{\circ} \mathrm{C}(\mathrm{a})$, the greatest number of consecutive days of $T_{\text {ave }} \geq 30{ }^{\circ} \mathrm{C}(\mathrm{b})$, the number of days of $T_{\max } \geq 35^{\circ} \mathrm{C}(\mathrm{c})$, and the greatest number of consecutive days of $T_{\max } \geq 35^{\circ} \mathrm{C}$ (d) from 1981 to $2017^{\dagger} .{ }^{\dagger} H T$ : high temperature. $T_{\text {ave }}$ : daily average temperature; $T_{\max }$ : daily maximum temperature

\section{Relationship between spikelet fertility and temperature, number of HT days}

To screen for rice agricultural traits related (data collected from 2004 to 2016) to the identification of HT hazard, the changes of temperature and measures of single-season rice yield were investigated (Table 1). A correlation was identified between measures of yield and temperature as well as measures of yield and the number of HT days. The relationships between spikelet fertility, temperature, and number of HT days were analyzed. As shown in Figure $11 a-d$, there were strong negative correlations between spikelet fertility and $\mathrm{T}_{\text {ave }}(\mathrm{P}=0.033 ;$ Fig. 11a), spikelet fertility and the number of days 
of $\mathrm{T}_{\text {ave }} \geq 30{ }^{\circ} \mathrm{C}(\mathrm{P}=0.020$; Fig. 11c), and spikelet fertility and the number of days of $\mathrm{T}_{\max } \geq 35^{\circ} \mathrm{C}(\mathrm{P}=0.005$; Fig. 11d $)$. However, spikelet fertility was not correlated with $\mathrm{T}_{\max }(\mathrm{P}=0.303$; Fig. $11 \mathrm{~b})$, and the number of consecutive HT days (not listed in this table). Thus, in addition to meteorological factors (temperature, number of HT days), spikelet fertility can also be used as an effective trait for the identification of HT hazard in single-season rice.

\section{Discussion}

Because of its geographical location and climate, Jiangxi is prone to HT hazard events. In this study, we found that HT hazard during the heading-flowering period in single-season rice occurred every year from 1981 to 2017 in Jiangxi. Moreover, air temperature $\left(\mathrm{T}_{\text {ave }}\right.$ and $\left.\mathrm{T}_{\max }\right)$ has generally increased since 2003 , and the number of slight, moderate, and severe HT hazard events has increased since 2003, with severe HT showing a significant increase $(\mathrm{P}<0.05)$. In addition, a greater number of HT hazard events of single-season rice was primarily distributed in the middle and northeast area of Jiangxi, which is consistent with the results of Huang et al. (2017).
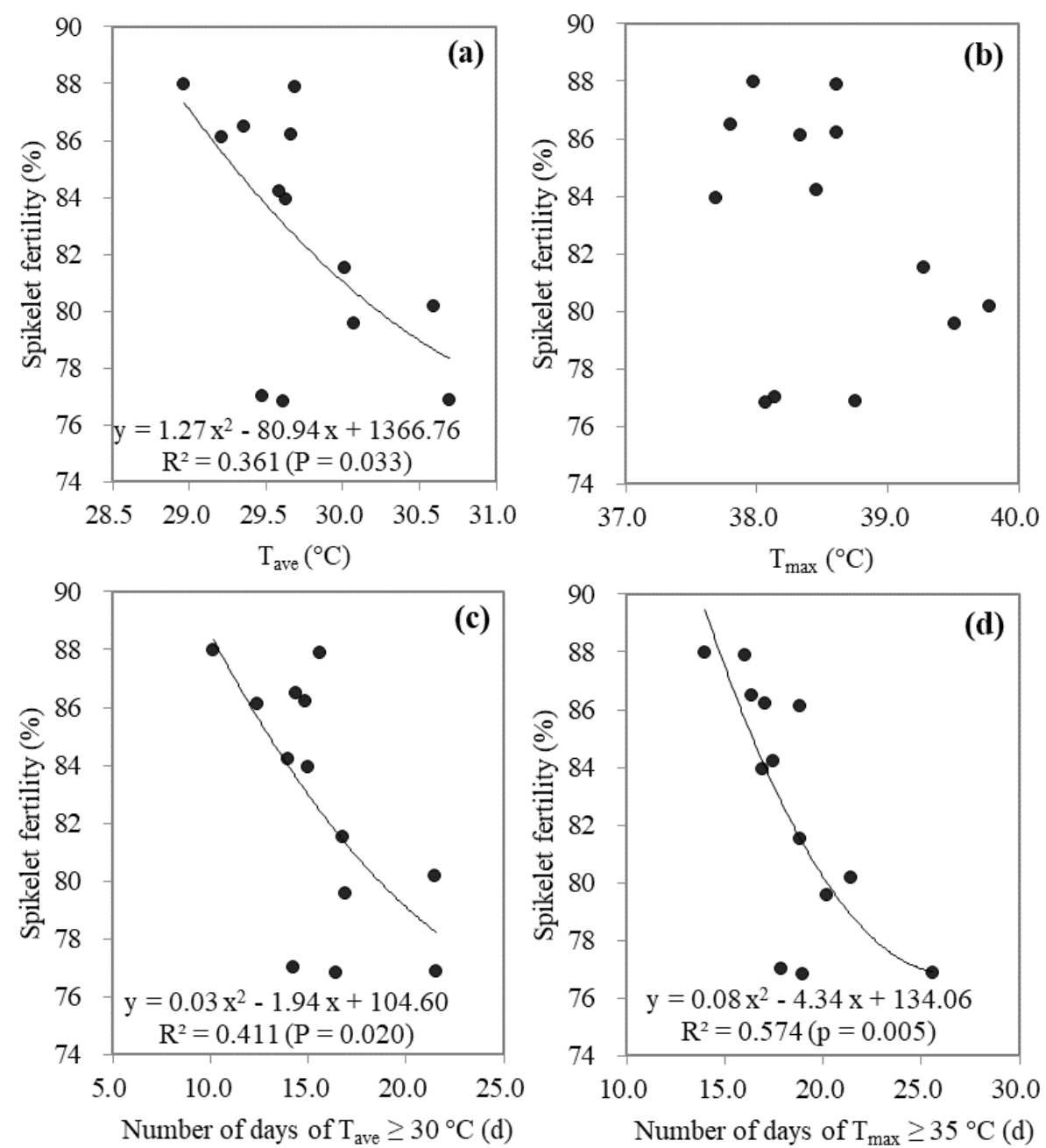

Figure 11. Correlations between spikelet fertility and $T_{\text {ave }}(a), T_{\max }(b)$, number of days of $T_{\text {ave }} \geq 30{ }^{\circ} \mathrm{C}(\mathrm{c})$, and number of days of $T_{\max } \geq 35^{\circ} \mathrm{C}(d)^{\dagger}$. ${ }^{\dagger} H T$ : high temperature. $T_{\text {ave: }}$ : daily average temperature; $T_{\max }$ : daily maximum temperature 
Table 1. Changes of temperature data and measures of single-season rice yield from 2004 to 2016

\begin{tabular}{|c|c|c|c|c|c|c|c|c|c|c|c|}
\hline Year & $\begin{array}{l}\mathbf{T}_{\text {ave }} \\
\left({ }^{\circ} \mathbf{C}\right)\end{array}$ & $\begin{array}{l}\mathbf{T}_{\max } \\
\left({ }^{\circ} \mathbf{C}\right)\end{array}$ & \begin{tabular}{|c|}
$\begin{array}{c}\text { Number of } \\
\text { days of } \\
T_{\text {ave }} \geq 30^{\circ} \mathrm{C} \text { (d) }\end{array}$ \\
\end{tabular} & $\mid \begin{array}{c}\begin{array}{c}\text { Number of } \\
\text { days of } \\
T_{\text {max }} \geq 35^{\circ} \mathrm{C} \text { (d) }\end{array} \\
\mid\end{array}$ & Varieties & $\begin{array}{c}\text { Effective } \\
\text { panicles } \\
\left(\mathbf{m}^{-2}\right)\end{array}$ & $\begin{array}{c}\text { Total } \\
\text { grains per } \\
\text { panicle }\end{array}$ & \begin{tabular}{|c|} 
Filled \\
grains per \\
panicle
\end{tabular} & $\begin{array}{l}\text { Spikelet } \\
\text { fertility } \\
(\%)\end{array}$ & $\begin{array}{c}\text { 1000-grain } \\
\text { weight }(\mathrm{g})\end{array}$ & $\begin{array}{c}\text { Actual } \\
\text { yield } \\
\left(\mathrm{kg} \cdot \mathrm{hm}^{-2}\right)\end{array}$ \\
\hline 2004 & 29.5 & 38.1 & 14.3 & 17.9 & Shanyou 63 & 16.9 & 129.6 & 99.8 & 77.0 & 28.3 & 7536.0 \\
\hline 2005 & 29.6 & 38.1 & 16.4 & 19.0 & Shanyou 63 & 15.5 & 140.2 & 107.7 & 76.8 & 29.1 & 7065.5 \\
\hline 2006 & 29.6 & 37.7 & 15.0 & 16.9 & II you 838 & 14.7 & 133.9 & 112.4 & 83.9 & 28.1 & 7151.1 \\
\hline 2007 & 30.7 & 38.8 & 21.5 & 25.6 & II you 838 & 14.7 & 152.3 & 117.1 & 76.9 & 29.6 & 7037.1 \\
\hline 2008 & 29.7 & 38.6 & 14.9 & 17.1 & II you 838 & 14.9 & 144.5 & 124.6 & 86.2 & 30.6 & 5233.3 \\
\hline 2009 & 29.7 & 38.6 & 15.6 & 16.1 & II you 838 & 15.9 & 123.0 & 108.1 & 87.9 & 30.7 & 7941.6 \\
\hline 2010 & 30.1 & 39.5 & 16.9 & 20.2 & II you 1308 & 15.0 & 175.7 & 139.8 & 79.6 & 27.5 & 8249.6 \\
\hline 2011 & 29.6 & 38.5 & 14.0 & 17.5 & II you 1308 & 15.4 & 170.4 & 143.5 & 84.2 & 28.1 & 8672.6 \\
\hline 2012 & 29.4 & 37.8 & 14.4 & 16.4 & Y liangyou 1 & 16.4 & 158.3 & 136.9 & 86.5 & 26.1 & 5512.9 \\
\hline 2013 & 30.6 & 39.8 & 21.5 & 21.4 & Y liangyou 1 & 17.5 & 156.4 & 125.4 & 80.2 & 25.6 & 8387.9 \\
\hline 2014 & 29.2 & 38.3 & 12.4 & 18.8 & Y liangyou 1 & 17.4 & 155.4 & 133.8 & 86.1 & 26.0 & 8718.9 \\
\hline 2015 & 29.0 & 38.0 & 10.1 & 14.0 & Y liangyou 1 & 17.6 & 157.9 & 138.9 & 88.0 & 26.3 & 8924.3 \\
\hline 2016 & 30.0 & 39.3 & 16.7 & 18.8 & Y liangyou 1 & 16.5 & 158.5 & 129.2 & 81.5 & 25.9 & 8765.4 \\
\hline
\end{tabular}

HT: high temperature. $\mathrm{T}_{\text {ave }}$ : average temperature; $\mathrm{T}_{\max }$ : maximum temperature; rice data of singleseason rice yield in seven representative regional trials, and temperature data were recorded by 15 national weather stations near the trials in Jiangxi Province; the data in 2017 is not available

Rice spikelets are highly susceptible to HT exposure during the heading-flowering period. HTs greater than $35{ }^{\circ} \mathrm{C}$ leads to poor anther dehiscence, low pollen production and pollen viability, and reduced pollen germination rate on the rice stigma, which dramatically reduces spikelet fertility (Jagadish et al., 2010; Zhao et al., 2018; Shi et al., 2018). There was no significant relationship between maximum temperature and spikelets per $\mathrm{m}^{2}$ (Peng et al., 2004). Spikelet fertility was reduced by $2.4 \%\left({ }^{\circ} \mathrm{C} \text { day }\right)^{-1}$ above a threshold of $33{ }^{\circ} \mathrm{C}$ (Jagadish et al., 2007). A controlled rice experiment conducted during meiosis, with six temperatures $\left(31,33,35,37,39\right.$, and $\left.41{ }^{\circ} \mathrm{C}\right)$ and three durations $(1,3$, and $5 \mathrm{~d})$, showed that temperatures below $33^{\circ} \mathrm{C}$ had no significant effect on spikelet fertility, but with the increase of temperature and its duration, the spikelet fertility decreased gradually; the daily relative spikelet fertility could be expressed in terms of temperature (Shi et al., 2008). In our study, spikelet fertility was negatively correlated to $\mathrm{T}_{\text {ave }}(\mathrm{P}<0.05)$ but not to $\mathrm{T}_{\max }(\mathrm{P}>0.05)$ under natural conditions in Jiangxi. Spikelet fertility was negatively correlated to the number of days of $\mathrm{T}_{\text {ave }} \geq 30{ }^{\circ} \mathrm{C}(\mathrm{P}<0.05)$ and the number of days of $\mathrm{T}_{\max } \geq 35^{\circ} \mathrm{C}(\mathrm{P}<0.01)$. Thus, in turn, spikelet fertility can be regarded as a morphological trait to evaluate HT hazard during the heading-flowering period (Prasad et al., 2006; Jagadish et al., 2010).

HT is not conducive to rice heading and flowering; therefore, measures to protect rice from HT stress should be taken. For example, heat-resistant rice varieties can be selected and/or exogenous substances can be sprayed on foliage to effectively protect rice against HT hazard. Based on decreases in spikelet fertility under HT, previous studies have shown that the cultivars ' $\mathrm{N} 22$ ' ( $O$. sativa ssp. indica rice from India) and 'IR64' (O. sativa indica rice from the Philippines) are heat-tolerant cultivars (Prasad et al., 2006; Jagadish et al., 2010). The exogenous application of plant growth regulators (ascorbic acid, alpha-tocopherol, brassinosteroids, methyl jasmonates, and triazoles), 6benzylaminopurine, boron, and abscisic acid during the flowering period of rice affected by HT has also been shown to have a substantial effect on cell membrane stability, sugar metabolism, pollen viability, and spikelet fertility (Fahad et al., 2016; Wu et al., 
2017; Shahid et al., 2018; Islam et al., 2018). In addition, avoiding HT is another effective method to reduce HT hazard. Rice with an early-morning flowering trait could allow for rice to avoid the hottest times of the day by blooming at a cooler temperature in the early morning (Ishimaru et al., 2010). Early-morning flowering rice exposed to elevated temperature could complete flowering before the air temperature reaches $35^{\circ} \mathrm{C}$ during the day, which can effectively mitigate heat-induced spikelet sterility (Hirabayashi et al., 2015). In accordance with the characteristics of historical HT, optimization of sowing date can enhance rice production by avoiding HT stress during the critical period (Khan et al., 2019). In our results, HT hazard events mainly occurred from July 11 to August 10, and severe HT hazard events occurred more frequently from July 21 to July 31 in Jiangxi Province. Furthermore, our data highlight that the temperatures of four consecutive days on July $22-25$ were the highest $\left(\mathrm{T}_{\text {ave }} \geq 29.6{ }^{\circ} \mathrm{C}\right.$, $\mathrm{T}_{\max } \geq 34.9^{\circ} \mathrm{C}$ ). Thus, it is necessary to consider defense measures, such as avoiding HT, selecting heat-resistant varieties, or spraying rice foliage with exogenous substances, during the heading-flowering period of rice.

\section{Conclusions}

In this paper, we show that HT hazard events (HT for $\geq$ three consecutive days) in single-season rice occurred every year from 1981 to 2017, while increased after 2003. HT mainly occurred from July 11 to August 10, and occurred more frequently from July 21 to July 31. In addition, a greater number of HT hazard events was mainly distributed in the middle and northeast area of Jiangxi. It is worth noting that there were strong negative correlations between spikelet fertility and $\mathrm{T}_{\text {ave }}$, days of $\mathrm{T}_{\text {ave }} \geq 30{ }^{\circ} \mathrm{C}$, and days of $\mathrm{T}_{\max } \geq 35{ }^{\circ} \mathrm{C}$. Thus, the results of this study highlight the need for a greater understanding of how to mitigate rice HT hazard. Future studies should be considered to establish a refined regional plan for the optimal sowing dates of different maturity rice varieties under global warming.

Acknowledgements. This research was funded by the National Natural Science Foundation of China (41965008), the Jiangxi Key Research and Development Program (20192BBFL60040; 20165ABC28008; 20171BBF60032), the Jiangxi Industrial Technology System Fund for Rice Field Comprehensive Breeding (JXARS-12), the Jiangxi Key Foundation (20152ACF6009), and the Jiangxi Meteorological Technology Foundation (JMTF20170221).

\section{REFERENCES}

[1] Chaturvedi, A. K., Bahuguna, R. N., Shah, D., Pal, M., Jagadish, S. V. K. (2017): High temperature stress during flowering and grain filling offsets beneficial impact of elevated $\mathrm{CO}_{2}$ on assimilate partitioning and sink-strength in rice. - Scientific Reports 7: 8227.

[2] Espe, M. B., Hill, J. E., Hijmans, R. J., McKenzie, K., Mutters, R., Espino, L. A., Leinfelder-Miles, M., van Kessel, C., Linquist, B. A. (2017): Point stresses during reproductive stage rather than warming seasonal temperature determine yield in temperate rice. - Global Change Biology 23: 4386-4395.

[3] Fahad, S., Hussain, S., Saud, S., Hassan, S., Ihsan, Z., Shah, A. N., Wu, C., Yousaf, M., Nasim, W., Alharby, H., Alghabari, F., Huang, J. (2016): Exogenously applied plant growth regulators enhance the morpho-physiological growth and yield of rice under high temperature. - Frontiers in Plant Science 7: 1250. 
[4] Hirabayashi, H., Sasaki, K., Kambe, T., Gannaban, R. B., Miras, M. A., Mendioro, M. S., Simon, E. V., Lumanglas, P. D., Fujita, D., Takemoto-Kuno, Y., Takeuchi, Y., Kaji, R., Kondo, M., Kobayashi, N., Ogawa, T., Ando, I., Jagadish, K. S., Ishimaru, T. (2015): $q E M F 3$, a novel QTL for the early-morning flowering trait from wild rice, Oryza officinalis, to mitigate heat stress damage at flowering in rice, O. sativa. - Journal of Experimental Botany 66: 1227-1236.

[5] Huang, J., Zhang, F., Xue, Y., Lin, J. (2017): Recent changes of rice heat stress in Jiangxi province, southeast China. - International Journal of Biometeorology 61: 623-633.

[6] IPCC (2013): Climate Change 2013: The Physical Science Basis. Contribution of Working Group I to the Fifth Assessment Report of the Intergovernmental Panel on Climate Change. - Cambridge, Cambridge University Press.

[7] Ishimaru, T., Hirabayashi, H., Ida, M., Takai, T., San-Oh, Y. A., Yoshinaga, S., Ando, I., Ogawa, T., Kondo, M. (2010): A genetic resource for early-morning flowering trait of wild rice Oryza officinalis to mitigate high temperature-induced spikelet sterility at anthesis. - Annals of Botany 106: 515-520.

[8] Islam, M. R., Feng, B., Chen, T., Fu, W., Zhang, C., Tao, L., Fu, G. (2018): Abscisic acid prevents pollen abortion under high-temperature stress by mediating sugar metabolism in rice spikelets. - Plant Physiology 165: 644-663.

[9] Jagadish, S. V., Craufurd, P. Q., Wheeler, T. R. (2007): High temperature stress and spikelet fertility in rice (Oryza sativa L.). - Journal of Experimental Botany 58: 16271635.

[10] Jagadish, S. V., Muthurajan, R., Oane, R., Wheeler, T. R., Heuer, S., Bennett, J., Craufurd, P. Q. (2010): Physiological and proteomic approaches to address heat tolerance during anthesis in rice (Oryza sativa L.). - Journal of Experimental Botany 61: 143-156.

[11] Khan, S., Anwar, S., Ashraf, M. Y., Khaliq, B., Sun, M., Hussain, S., Gao, Z. Q., Noor, H., Alam, S. (2019): Mechanisms and adaptation strategies to improve heat tolerance in rice. A review. - Plants (Basel) 8: 508.

[12] Kim, H. Y., Ko, J., Kang, S., Tenhunen, J. (2013): Impacts of climate change on paddy rice yield in a temperate climate. - Global Change Biology 19: 548-562.

[13] Madan, P., Jagadish, S. V., Craufurd, P. Q., Fitzgerald, M., Lafarge, T., Wheeler, T. R. (2012): Effect of elevated $\mathrm{CO}_{2}$ and high temperature on seed-set and grain quality of rice. - Journal of Experimental Botany 63: 3843-3852.

[14] Mohammed, A. R., Tarpley, L. (2009): High nighttime temperatures affect rice productivity through altered pollen germination and spikelet fertility. - Agricultural and Forest Meteorology 149: 999-1008.

[15] Peng, S., Huang, J., Sheehy, J. E., Laza, R. C., Visperas, R. M., Zhong, X., Centeno, G. S., Khush, G. S., Cassman, K. G. (2004): Rice yields decline with higher night temperature from global warming. - Proceedings of the National Academy of Sciences of the United States of America 101: 9971-9975.

[16] Prasad, P. V. V., Boote, K. J., Allen Jr, L. H., Sheehy, J. E., Thomas, J. M. G. (2006): Species, ecotype and cultivar differences in spikelet fertility and harvest index of rice in response to high temperature stress. - Field Crops Research 95: 398-411.

[17] Ray, D. K., Gerber, J. S., MacDonald, G. K., West, P. C. (2015): Climate variation explains a third of global crop yield variability. - Nature Communications 6: 5989.

[18] Shahid, M., Nayak, A. K., Tripathi, R., Katara, J. L., Bihari, P., Lal, B., Gautam, P. (2018): Boron application improves yield of rice cultivars under high temperature stress during vegetative and reproductive stages. - International Journal of Biometeorology 62: 1375-1387.

[19] Shi, C. L., Q., J. Z., Zheng, J. C., Tang, R. S. (2008): Quantitative analysis on the effects of high temperature at meiosis stage on seed-setting rate of rice florets. - Acta Agronomica Sinica 34: 627-631 (in Chinese). 
[20] Shi, W., Li, X., Schmidt, R. C., Struik, P. C., Yin, X., Jagadish, S. V. K. (2018): Pollen germination and in vivo fertilization in response to high-temperature during flowering in hybrid and inbred rice. - Plant Cell and Environment 41: 1287-1297.

[21] Stuerz, S., Asch, F. (2019): Responses of rice growth to day and night temperature and relative air humidity-dry matter, leaf area, and partitioning. - Plants (Basel) 8: 521.

[22] Tang, S., Zhang, H., Liu, W., Dou, Z., Zhou, Q., Chen, W., Wang, S., Ding, Y. (2019): Nitrogen fertilizer at heading stage effectively compensates for the deterioration of rice quality by affecting the starch-related properties under elevated temperatures. - Food Chemistry 277: 455-462.

[23] Van Oort, P. A. J., Zwart, S. J. (2018): Impacts of climate change on rice production in Africa and causes of simulated yield changes. - Global Change Biology 24: 1029-1045.

[24] Wang, P., Zhan, Z., Chen, Y., Wei, X., Feng, B., Tao, F. (2016): How much yield loss has been caused by extreme temperature stress to the irrigated rice production in China? Climatic Change 134: 635-650.

[25] Wu, C., Cui, K., Wang, W., Li, Q., Fahad, S., Hu, Q., Huang, J., Nie, L., Mohapatra, P. K., Peng, S. (2017): Heat-induced cytokinin transportation and degradation are associated with reduced panicle cytokinin expression and fewer spikelets per panicle in rice. Frontiers in Plant Science 8: 371.

[26] Yang, B., Shen, S., Tao, S., Li, Q., Zou, X. (2012): Spatial and temporal pattern of rice heat injury in Jiangxi. - Chinese Journal of Agrometeorology 33: 615-622 (in Chinese).

[27] Yang, J., Chen, X., Zhu, C., Peng, X., He, X., Fu, J., Ouyang, L., Bian, J., Hu, L., Sun, $\mathrm{X}$., Xu, J., He, H. (2015): Using RNA-seq to profile gene expression of spikelet development in response to temperature and nitrogen during meiosis in rice (Oryza sativa L.). - PLoS One 10: e0145532.

[28] Zhao, Q., Zhou, L., Liu, J., Du, X., Asad, M. A., Huang, F., Pan, G., Cheng, F. (2018): Relationship of ROS accumulation and superoxide dismutase isozymes in developing anther with floret fertility of rice under heat stress. - Plant Physiology and Biochemistry 122: 90-101. 